\title{
Effect of Different Surface Treatments of Glass Fiber Posts on their Surface Roughness and Flexure Properties
} \author{
October City, Egypt
}

Mai Hesham ${ }^{1,2 *}$ (]) Ahmed Hashem² ${ }^{2}$, Faisal Hamza' ${ }^{1}$

${ }^{1}$ Department of Dental Biomaterials, Faculty of Dentistry, October University for Modern Sciences and Arts, $6^{\text {th }}$ of October City, Egypt; ${ }^{2}$ Department of Fixed Prosthodontics, Faculty of Dentistry, October University for Modern Sciences and Arts, $6^{\text {th }}$ of

\begin{abstract}
AIM: This study aimed to assess the effect of different surface treatments on the surface roughness and flexure properties of glass fiber posts "GFPs."

MATERIALS AND METHODS: A total of 40 GFPs were divided into four groups $(n=10)$ : $G C$ - no surface treatment (control), GSB - sandblasted, GHF - hydrofluoric acid etched, and GL - Er: YAG laser irradiated. Surface roughness was detected using surface profilometer and the 3-points bending flexural test measured flexural strength and elastic modulus.

RESULTS: GSB showed the highest mean roughness followed by GHF, then GL, while GC had lowest roughness mean value. The 3 points bending test results were calculated and recorded, GSB exhibited the highest flexure stress (MPa) compared to GHF and GL. Modulus of elasticity (GPa) showed significant differences between the tested groups, GSB showed the highest modulus of elasticity compared to GHF and GL, while GC showed insignificant differences with all tested groups.

CONCLUSION: Different surface treatments postulated in this study showed alternations of GFPs surfaces without
\end{abstract} jeopardizing the mechanical properties of GFPs.

\section{Introduction}

Endodontic therapyis mostly followed by postand core restorations attempting to restore the missed tooth structure and provide crown retention [1], [2], [3]. For optimum results, materials used for post-fabrication must exhibit physical and mechanical properties like that of dentin; closely matching elastic moduli results in homogenous distribution of occlusal stresses along with the roots, thus fracture risk is reduced, moreover, posts should be able to bond to the tooth structure and should be biocompatible in the oral environment [4], [5], [6].

Different post materials are marketed; fiberreinforced posts (FRC) are in use showing acceptable results both clinically and in practical research, due to "dentin-like" modulus of elasticity and favorable esthetic properties compared to metal posts [7], [8]. Fiber-based posts are composed of an epoxy resin matrix or its derivatives into which fibers are embedded for structure reinforcement and properties improvement [3], [9].

Restoring an endodontically treated tooth within the high-demand esthetic zone, led to the introduction of esthetic posts; glass fiber-reinforced composite resin posts (FRC), and yttrium stabilized zirconium-based ceramic posts [9], [10].

They are characterized by exhibiting an elastic modulus equal to that of dentin combined with their high durability [9], [10]. In glass fiber posts (GFPs), short length glass fibers are randomly distributed throughout the resin matrix, the incorporation of glass fibers reduces stresses produced at the interfaces, thus allowing the restored tooth to mimic the mechanical behavior of natural tooth structure [11], [12].

Surface treatments of dental structures and restorative materials are used techniques for roughening by removal of the superficial epoxy resin matrix and exposing the internal glass fibers, thus improving their general adhesion properties [1], [10], [13], [14]. Roughening is accomplished by mechanical treatments (sandblasting) or chemical treatments (etching with hydrofluoric acids or hydrogen peroxides) [1], [14].

In sandblasting; the post surface is subjected to a high-pressure stream of aluminum oxide (Al2O3) particles having different particle sizes, abrading the superficial layer resulting in roughened surface [10]. While, acid etching using hydrofluoric acid works by forming micro spaces between the exposed fibers, 
consequently improving the bond between the luting agent and the post surface [14].

Recently, laser etching technology has invaded dentistry, types employed are argon laser, neodymiumdoped yttrium aluminum garnet (Nd: YAG) laser, diode laser, erbium-doped YAG (Er: YAG), and erbium chromium (Er, Cr: YSGG) [9].

However, there is scarce information about GFP different surface treatments influence their surface roughness and mechanical properties. Accordingly, this study was designed to evaluate and compare the effect of different surface treatments of GFP on surface roughness and flexure properties.

\section{Materials}

A total of 60 GFPs size\#4 (GLASSIX radiopaque fiber post, NORDIN, Switzerland) were used in this study with dimensions of $1.5 \mathrm{~mm}$ in diameter and $20 \mathrm{~mm}$ in length. Posts were divided into four groups $(n=15)$ according to the surface treatment performed;

Group 1 (GC): No surface treatment.

Group 2 (GSB): Mechanical treatment "sandblasting." Posts were sandblasted with 110 um diameter aluminum oxide particles at a pressure of 2-3 bars (ALUKOR, Germany), the tip of the sandblasting device was held perpendicularly to the post at $1 \mathrm{~cm}$. During the procedure, the post was rotated so that the aluminum oxide particles would be blasted on its entire surface for $15 \mathrm{~s}$, posts were then cleaned with compressed air for 15 $s$ to remove the residual particles [1], [10].

Group 3 (GHF): Chemical treatment "using hydrofluoric acid 9.6\%." Posts were etched for $60 \mathrm{~s}$ at room temperature then rinsed for $60 \mathrm{~s}$ and dried with air blow [1], [10].

Group 4 (GL): Laser irradiation (Er: YAG laser $2940 \mathrm{~nm}$ ). Posts were irradiated with an Er: YAG (2940 nm) with energy $150 \mathrm{~mJ}$, output power $1.5 \mathrm{~W}$, and repetition rate of $10 \mathrm{~Hz}$ in a pulsatile non-contact mode (angled handpiece, $0.9 \mathrm{~mm}$ spot size). The laser beam was delivered perpendicularly forming a $90^{\circ}$ angle with the post surface at a constant distance of $1 \mathrm{~mm}$ for $60 \mathrm{~s}$ undercooling.

\section{Methods}

- $\quad$ According to the ethics guidelines, no ethical approval was needed as this article was not conducted on animals or humans

- $\quad$ No informed consent was needed as it was not conducted on humans.

\section{Surface roughness evaluation}

A total of 20 GFPs were subjected to surface roughness evaluation ( $n=5)$, the test was conducted using a contact profilometer (Elcometer 224/2, Elcometer Instruments, Great Britain). Three readings were obtained from the needle passing across the length of each post; finally, a roughness average of the posts was calculated for each group [15].

\section{Three-point bending testing}

A total of 40 GFPs (10 from each group) were subjected to a bending test. The GFPs were stored at 37c for $48 \mathrm{~h}$ before testing. The mean diameter of each post was measured in five different regions using a digital caliper "Mitutoyo digital caliper, Japan." Posts were loaded to failure in 3-point bending by the ISO standard number 10477 (10.0 mm span, $0.5 \mathrm{~mm} / \mathrm{min}$ crosshead speed, $2 \mathrm{~mm}$ cross-sectional diameter of the loading tip) with a $500 \mathrm{~N}$ load cell, using a universal testing machine "Instron universal testing machine model 3354 Instron instruments England." Flexural strength $(\sigma) ; \sigma=8 \mathrm{~F}_{\text {max }} \mathrm{L} / \pi \mathrm{d}^{3}$ (in MPa) where, $F_{\text {Max }}$ is the applied load (in Newton) at the highest point of the loaddeflection curve, $L$ is the span length $(6.0 \mathrm{~mm})$, and $d$ is the diameter of the posts (in $\mathrm{mm}$ ) [3], [6], [12], [15].

\section{Modulus of elasticity}

From the values obtained by the 3-point bending test, the modulus of elasticity (Ef) was calculated by the following equation: $E f=S 4 L 3 / 3 d 4$, where $S$ is the stiffness, $L$ is the distance between the support points in $\mathrm{mm}(8 \mathrm{~mm})$, and $\mathrm{d}$ is the diameter of the post. $S$ was obtained using the following equation: $F=S / D$, where $F$ is the maximum load value in Newton and D is the deflection value (in $\mathrm{mm}$ ) [16].

\section{Statistical analysis}

Data explored for normality using KolmogorovSmirnov test. One-way ANOVA was used to compare between tested groups followed by Tukey HSD post hoc testformulticomparison. Asignificant level was setat 0.05 $(\alpha=0.05)$. Statistical analysis was done using Statistical Package for the Social Sciences (IBM SPSS Statistics for Windows, Version 23.0. Armonk, NY: IBM Corp.)

\section{Results}

\section{Surface roughness}

GSB $(5.5 \pm 0.6)$ showed the highest surface roughness followed by GHF $(3.9 \pm 0.3)$ then $G L$ (3.2 \pm 0.2$)$ while GC exhibited the lowest surface 
roughness $(2.1 \pm 0.4)$ with a significant difference between all the groups at $p \leq 0.001$.

Table 1: Mean and standard deviation (SD) for surface roughness of the tested groups

\begin{tabular}{|c|c|c|c|c|c|c|c|c|c|}
\hline \multirow[t]{2}{*}{ Group/test } & \multicolumn{2}{|c|}{ Control } & \multicolumn{2}{|l|}{ Laser } & \multicolumn{2}{|c|}{ Chemical } & \multicolumn{2}{|c|}{ Mechanical } & \multirow[t]{2}{*}{$p$-value } \\
\hline & Mean & SD & Mean & SD & Mean & SD & Mean & SD & \\
\hline Roughness & $2.1^{\mathrm{d}}$ & 0.4 & $3.2^{\circ}$ & 0.2 & $3.9^{6}$ & 0.3 & $5.5^{\mathrm{a}}$ & 0.6 & $\leq 0.001^{*}$ \\
\hline
\end{tabular}

\section{Three-point bending test}

1. Maximum flexure load $(\mathrm{N})$

GC showed the highest flexural load value $(46.9 \pm 5.6)$ followed by GHF $(44.1 \pm 7.9)$ then GSB $(43 \pm 6 N)$, while GL exhibited the lowest mean value $(42.2 \pm 8)$ with no significant difference resulted between all the tested groups at $p=0.481$, as shown in Table 2 and Figure 2.

Table 2: Mean and standard deviation (SD) for flexure stress at maximum flexure load (MPa) of the tested groups

\begin{tabular}{|c|c|c|c|c|c|c|c|c|}
\hline \multirow[t]{2}{*}{ Group/test } & \multicolumn{2}{|c|}{ Control } & \multicolumn{2}{|l|}{ Laser } & Chemical & \multicolumn{2}{|c|}{ Mechanic } & $p$-value \\
\hline & Mean & SD & Mean & SD & Mean SD & Mean & SD & \\
\hline Maximum flexure load $(\mathrm{N})$ & 46.9 & 5.6 & 42.2 & 8.7 & 44.1 & 43.0 & 6.0 & $0.481 \mathrm{NS}$ \\
\hline
\end{tabular}
Different letters within each row indicate a significant difference.

Flexure stress at maximum flexure load ( $\mathrm{MPa})$ GSB showed the highest flexure stress mean value $(697.1 \pm 96.9 \mathrm{~N})$ at maximum flexure load (MPa) compared to GHF $(572.9 \pm 102.6 \mathrm{~N})$ then $\mathrm{GL}(548 \pm 112.7 \mathrm{~N})$ with a significant difference resulted between all the tested groups at $p=0.009$, while the control group showed insignificant difference with all tested treatments, as shown in Table 3 and Figure 3.

Table 3: Mean and standard deviation (SD) for flexure stress at maximum flexure load ( $\mathrm{MPa}$ ) of the tested groups

\begin{tabular}{|c|c|c|c|c|c|c|c|}
\hline \multirow{2}{*}{ Group/test } & \multicolumn{2}{|l|}{ Control } & \multicolumn{2}{|l|}{ Laser } & Chemical & \multirow{2}{*}{\multicolumn{2}{|c|}{$\frac{\text { Mechanical }}{\text { Mean SD }}$-value }} \\
\hline & Mean & SD & Mean & SD & Mean SD & & \\
\hline $\begin{array}{l}\text { Flexure stress at } \\
\text { maximum flexure } \\
\text { load (MPa) }\end{array}$ & $609.5^{\mathrm{ab}}$ & 73.3 & $548.0^{6}$ & 112.7 & $572.9^{b} \quad 697.1$ & $\begin{array}{ll}102.6 \quad 96.9\end{array}$ & $0.009^{*}$ \\
\hline
\end{tabular}

3. Modulus of elasticity (GPa)

GSB showed the highest modulus $(28.9 \pm 2.9)$ followed by GHF $(23.6 \pm 4)$ then GL $(23 \pm 4.6)$ with a significant difference between all the tested groups at $p=0.003$, while GC showed insignificant difference with all tested groups, as shown in Table 4 and Figure 4.

Table 4: Mean and standard deviation (SD) for modulus of elasticity $(\mathrm{GPa})$ of the tested groups

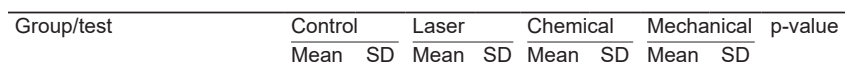
\begin{tabular}{llllllllll}
\hline Modulus of elasticity (GPa) & $25.8^{\mathrm{ab}}$ & 2.3 & $23.0^{\mathrm{b}}$ & 4.6 & $23.6^{\mathrm{b}}$ & 4.0 & $28.9^{\mathrm{a}}$ & 2.9 & $0.003^{*}$ \\
\hline
\end{tabular} Different letters within each row indicate a significant difference. $p \leq 0.003^{\star}$

\section{Discussion}

FRC are more frequently used than cast posts for the retention of previously endodontically treated teeth, due to their better retentive properties, lower incidence of root fracture, combined with more favorable esthetics. Their success depends on the bond strength between resin cement, dentin, and post [2], [16]. GFPs are characterized by exhibiting modulus of elasticity closely matching to that of dentin, they are biocompatible, they also demonstrate; high durability, resistance to corrosion, and superior esthetics [17].

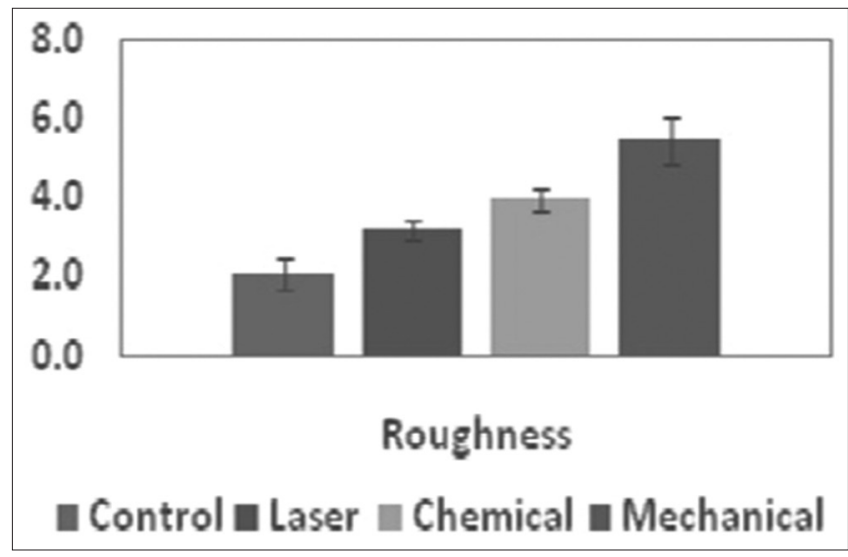

Figure 1: Bar chart for mean roughness of the tested groups

Debonding between posts and resin materials remains the most common cause of post-failure. Different surface treatments have been postulated aiming to modify the surface of the post and improving the interaction between the post and the resin cement without jeopardizing their mechanical properties, consequently, their clinical performance is increased [3], [14], [17].

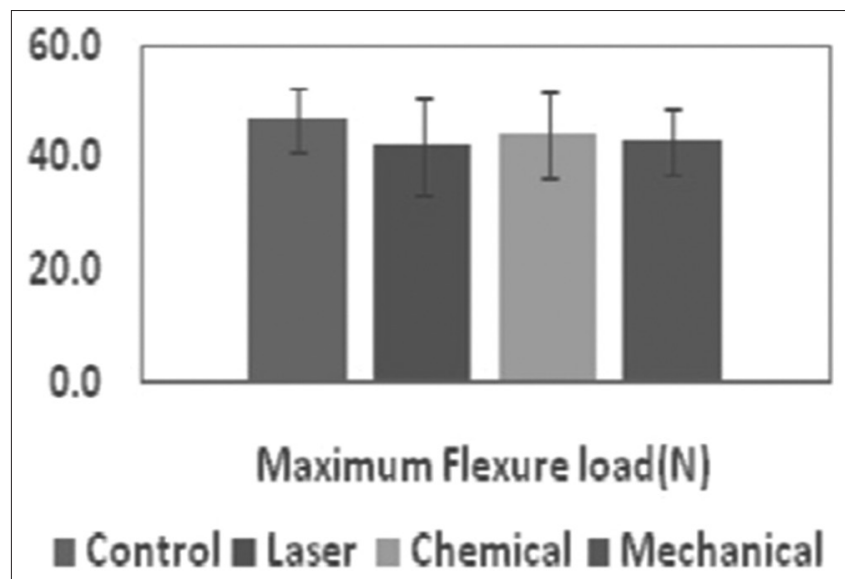

Figure 2: Bar chart for mean flexure stress at maximum flexure load $(\mathrm{MPa})$ of the tested groups

In the present study, a total of 60 GFPs were randomly divided into four groups $(n=15)$; GC, GSB, GHF, and GL. GHF posts were chemically treated using hydrofluoric acid (HF); $\mathrm{HF}$ is considered as a weak acid; however, it has a strong ability to etch glass surfaces with significant surface alterations, HF was used at a concentration of $9.6 \%$ due to its efficiency in surface etching without affecting strength [1], [10], [14]. GL posts were irradiated by Er: YAG laser at a power of $1.5 \mathrm{~W}$, since it does not damage the glass fibers but at the same time clears the epoxy resin coating over the surface of the posts, potentially allowing silane coupling agent to chemically interact with exposed glass fibers [17]. 


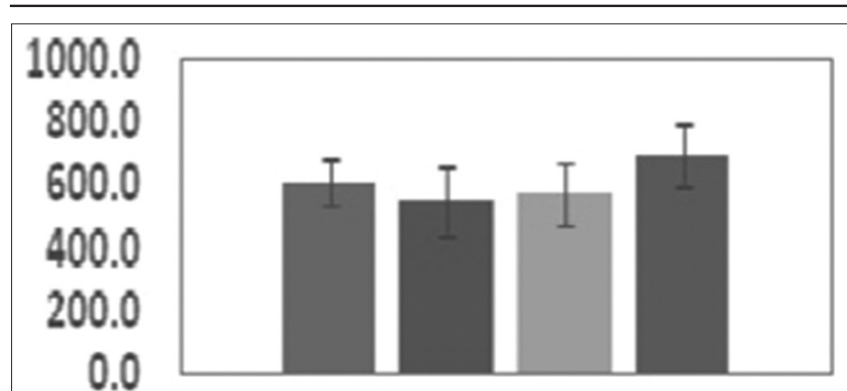

Flexure stress at Maximum Flexure load(MPa)

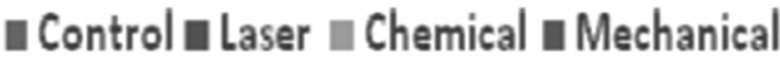

Figure 3: Bar chart for mean flexure stress at maximum flexure load (MPa) of the tested groups

Results of surface roughness showed that there was a significant difference between all tested groups, GSB exhibited the highest mean value followed by GHF, this might be due to the high speed of AL2O3 particles impacting the posts surfaces consequently, larger contact area, and high surface roughness. This was by Akin et al. in 2014 and Maroulakos et al. in 2019 [18], [19].

GL showed a lower mean value when compared to GSB and GHF, but higher than that of the control group with a significant difference. The GFPs irradiated with laser Er: YAG laser resulted in the removal of polymeric matrix of a post by ablation, exposing the fibers which increase the final surface roughness. Laser parameters in terms of intensity, frequency, wavelength, and ablation rate are the deciding factors to obtain optimal roughness values [19].

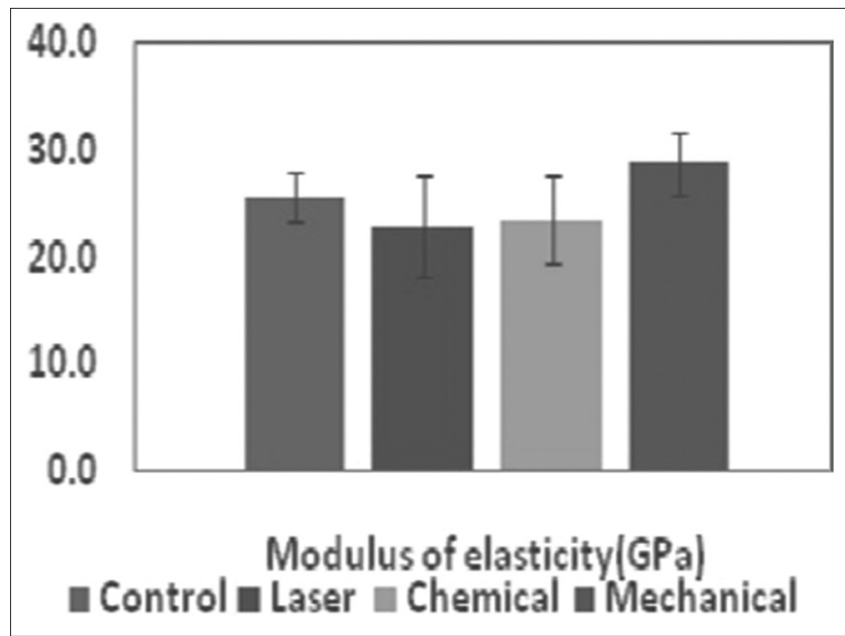

Figure 4: Bar chart for mean modulus of elasticity (GPa) of the tested groups

Surface roughness results in GL can be explained by the fact that an Er wave is well-absorbed by water, erbium lasers work through a pulsed beam system, fiber delivery system, and laser tip with water. Water is incorporated for cooling and reducing heat generation. Since laser radiation is well absorbed by water; water reaches the boiling point and causes microexplosion of the irradiated material. This action breaks up the microstructure into small pieces and dissipates them at the same time. As this explosion occurs in water, it is so-called a preparation induced by water. Therefore, a water spray is used for cooling [20], [21].

The flexure strength parameter is the determinant of the fracture resistance; higher values indicate that a sample is more resistant to fracture.

The flexural strength depends on the specimen configuration and is calculated by the highest load a sample can withstand. The flexural modulus is the property that defines the flexibility of a sample; the higher values, the stiffer the material, while lower values indicate higher flexibility by taking into consideration the elastic behavior of a sample within a load range that will not cause plastic deformation [4], [5]. The 3-point bending test is determined by some factors such as the span distance, the post shape, design, and diameter of the fiber post [22].

In the present study, results of flexure stress at maximum flexural load showed that GC exhibited insignificant differences with all tested groups. GSB showed the highest mean value when compared to GHF and GL with a statistically significant difference. This was by Soares et al. in 2008 [23], they analyzed the influence of airborne-particle abrasion on the mechanical properties of carbon/epoxy and glass/ bis-GMA fiber- reinforced resin posts, concluding that airborne-particle abrasion resulted in fibers discontinuities or even fibers fractures without jeopardizing the mechanical properties of the post.

This was by Braga et al. in 2012 [16] who assessed the influence of surface treatments of FRC on their flexural strength, modulus of elasticity, and morphology. They concluded that the flexural strength of FRC abraded with airborne particles was superior to those treated with HF.

On the contrary, Zicari et al. in 2012 [24] concluded that airborne-particle abrasion is considered aggressive surface treatment, because it resulted in volumetric reduction and plastic deformation of the posts, jeopardizing their mechanical and physical properties.

Results of the current study revealed that GSB had the highest modulus of elasticity mean value followed by GHF then GL with significant differences; this can be attributed to the reduction in the post diameter after surface treatment, which was confirmed by measurements made in the posts after treatment. The reduction of the post diameter is related to the modulus of elasticity since it is calculated by the equation $\mathrm{Ef}=\mathrm{S} 4 \mathrm{~L} 3 / 3 \pi \mathrm{d} 4$, which indicated that the modulus of elasticity is inversely proportional to diameter [9], [12], [24], [25]. 
However, Braga et al. in 2012 [16], according to their results, concluded that chemical treatment did not alter the post diameter and therefore did not affect its elastic modulus.

In the present study, GL recorded the lowest mean values of flexural strength and modulus of elasticity, which might be related to the damage in the interfiber area, which had led to the separation between the fibers forming gaps which might be the main cause of the weakness of the internal structure of GFPs, explaining the dropping of strength values of GL posts, this was supported by Akin et al. in 2014 [18] who reported that sandblasting produced more gentle damage and superficial effect on the post structure more than Er: YAG laser irradiation.

\section{Conclusion}

Within the limitations of the current study, it c different post surface treatments did not interfere with the flexural properties of GFPs. Flexural properties of the treated fiber posts showed statistically insignificant differences with the untreated posts despite the surface treatments performed. Different surface treatments cause significant changes in the post's surface roughness which might increase post retentive properties.

\section{References}

1. Gençoglu N, Sezgin P, Gündoğar M, Şivet C. The effect of surface treatments on the bond strength of fiber post to root canal dentin. Marmara Dent J. 2013;1:35-8.

2. Bonfante G, Kaizer OB, Pegoraro LF, Valle AL. Tensile bond strength of glass fiber posts luted with different cements. Braz Oral Res. 2007;21(2):159-64. http://doi.org/10.1590/ s1806-83242007000200011 PMid:17589652

3. Stewardson DA, Shortall AC, Marquis PM, Lumley PJ. The flexural properties of endodontic post materials. Dent Mater. 2010;26(8):730-6. http://doi.org/10.1016/j.dental.2010.03.017 PMid:20413150

4. Biały M, Szust A, Napadłek P, Dobrzyński M, Więckiewicz W. The three-point bending test of fiber-reinforced composite root canal posts. Adv Clin Exp Med. 2020;29(9):1111-6. http://doi. org/10.17219/acem/125426

PMid:33001590

5. Plotino G, Grande NM, Bedini R, Pameijer $\mathrm{CH}$, Somma F. Flexural properties of endodontic posts and human root dentin. Dent Mater. 2007;23(9):1129-35. http:// doi. org/10.1016/j dental.2006.06.047. PMid: 17116326

6. Novais VR, Quagliatto PS, Bona AD, Sobrinho LC, Soares CJ. Flexural modulus, flexural strength, and stiffness of fiber-reinforced posts. Indian J Dent Res. 2009;20(3):277-81. http://doi.org/10.4103/0970-9290.57357

PMid: 19884708

7. Peña VA, Darriba IL, Valea MC, Rivera FG. Mechanical properties related to the microstructure of seven different fiber reinforced composite posts. J Adv Prosthod. 2016;8(6):433-8. http://doi.org/10.4047/jap.2016.8.6.433

PMid:28018560

8. Mishra L, Khan AS, Velo MM, Panda S, Zavattini A, Rizzante FA et al. Effects of surface treatments of glass fiber-reinforced post on bond strength to root dentine: A systematic review. Materials 2020;13(8):1967. http://doi.org/10.3390/ma13081967 PMid:32340106

9. Cheleux N, Sharrock PJ. Mechanical properties of glass fiber- reinforced endodontic posts. Acta Biomater. 2009;5(8):3224-30. http://doi.org/10.1016/j.actbio.2009.04.008 PMid:19428317

10. El Mekkawi W, Mohammed S. The effect of different surface treatments on light transmittance and fracture resistance of fiber posts. Alazhar Dent J Grils. 2018;5(3):267-75.

11. Novais VB, Rodrigues RB, Júnior PC, Lourenço CS, Soares CJ. Correlation between the mechanical properties and structural characteristics of different fiber posts systems. Braz Dent J. 2016;27(1):46-51. http://doi.org/10.1590/0103-6440201600377 PMid:27007345

12. Loukil M, Hassine WB, Limam O, Kotronis P. Experimental determination of GFRC tensile parameters from three-point bending tests using an analytical damage model. Constr Build Mater J. 2019;223(30):477-90.

13. Monticelli F, Ferrari M, Toledano M. Cement system and surface treatment selection for fiber post luting. Med Oral Patol Oral Cirug Bucal. 2008;13(3):E214-21.

PMid: 18305446

14. Machado AC, Vilela AL, Souza PG, Pereira AG, Raposo LH, Faria-E-Silva AL, et al. Critical analysis of fiber post surface treatment: A review. Biosci J. 2014;30(3):914-24.

15. Kürkçüoğlu I, Küçükeşmen HC, Ozkir SE, Yilmaz B. Effect of surface treatment on roughness and bond strength of CAD-CAM multidirectional glass fiber-reinforced composite resin used for implant-supported prostheses. Polym Int. 2021;70(8):1153-8

16. Braga NM, Souza-Gabriel AE, Messias DC, Rached-Junior FJ, Oliveira CF, Silva RG, et al. Flexural properties, morphology and bond strength of fiber-reinforced posts: influence of post pretreatment. Braz Dent J. 2012;23(6):679-85.

17. Poplai G, Jadhav SK, Hegde V. Surface analysis of glass fiber posts after pretreatment with Er: YAG laser: An SEM study. J Dent Lasers. 2013;7(2):72-6.

18. Akin GE, Akin H, Sipahi C, Piskin B, Kirmali O. Evaluation of surface roughness and bond strength of quartz fiber posts after various pre-treatments. Acta Odontol Scand. 2014;72(8):1010-6. http://doi.org/10.3109/00016357.2014.939710 PMid:25139129

19. Maroulakos G, Wanserski MW, Wanserski MM, Schuler EJ, Egan CP, Thompson GA. Effect of airborne-particle abrasion on 3-dimensional surface roughness and characteristic failure load of fiber-reinforced posts. J Prosthet Dent. 2019;121(3):461-9. http://doi.org/10.1016/j.prosdent.2018.07.007 PMid:30554821

20. Abd El Halim S, Raafat R, EIGanzory A. ESEM analysis of enamel surface morphology etched with ER,CR: YSGG laser and phosphoric acid: In vitro study. Egypt Dent J. 2017;63:941-7.

21. Tarek M, Msoleh I, Zaghloul H. Effect of Er, Cr: YSGG laser versus acid etching surface treatment on the surface roughness and topography of two pressable lithium disilicate ceramics. "In-vitro study". Egypt Dent J. 2021;67:1571-81. 
22. Aksonmuang J, Chuenarrom C, Chittithaworn N. Effects of various etching protocols on the flexural properties and surface topography of fiber-reinforced composite dental posts. Dent Mater J. 2017;36(5):614-21. http://doi.org/10.4012/ dmj.2016-290

PMid:28566672

23. Soares CJ, Santana FR, Pereira JC, Araujo TS, Menezes MS Influence of airborne-particle abrasion on mechanical properties and bond strength of carbon/epoxy and glass/bis-GMA fiber- reinforced resin posts. J Prosthet Dent. 2008;99(6):44454. http://doi.org/10.1016/S0022-3913(08)60106-7

\section{PMid:18514666}

24. Zicari F, De Munck J, Scotti R, Naert I, Van Meerbeek B. Factors affecting the cement-post interface. Dent Mater. 2012;28(3):28797. http://doi.org/10.1016/j.dental.2011.11.003 PMid:22169674

25. Schmage P, Cakir FY, Nergiz I, Pfeiffer P. Effect of surface conditioning on the retentive bond strengths of fiber reinforced composite posts. J Prosthet Dent. 2009;102(6):368-77. http:// doi.org/10.1016/ S0022-3913(09)60196-7

PMid:19961995 